\title{
Offshoring Technology Innovation: A Case Study of Rare-earth Technology
}

\author{
BRIAN J. FIFAREK \\ Carnegie Mellon University \\ Engineering and Public Policy \\ 129 Baker Hall \\ 5000 Forbes Avenue \\ Pittsburgh, PA 15213 \\ Tel: (412) 268-2125 \\ e-mail: fifarek@cmu.edu \\ FRANCISCO M VELOSO \\ Carnegie Mellon University \\ Engineering and Public Policy \\ 129 Baker Hall \\ 5000 Forbes Avenue \\ Pittsburgh, PA 15213 \\ Tel: (412) 268-4640 \\ e-mail: fveloso@cmu.edu \\ CLIFF I. DAVIDSON \\ Carnegie Mellon University \\ Engineering and Public Policy \\ 129 Baker Hall \\ 5000 Forbes Avenue \\ Pittsburgh, PA 15213 \\ Tel: (412) 268-2951 \\ e-mail: cliff@cmu.edu
}




\title{
Offshoring Technology Innovation:
}

\section{A Case Study of the Rare-earth Technology}

Forthcoming at Journal of Operations Management

\begin{abstract}
Many US firms are improving their individual competitiveness by offshoring manufacturing operations, services and, increasingly, knowledge work. Although research to date has maintained that these practices are beneficial to the offshoring firm and national economies, by reducing costs and expanding markets, little is known about the longer term effect of offshoring on the rate of innovation of home economies. This paper suggests that offshoring practices have adverse effects on innovation at the national home base. The analysis uses patents in the rare earth element industry, a high tech area which is among those that have evolved the furthest towards outsourcing and relocation away from the US and to developing countries. Looking at the rare earth industry can provide insights in identifying potential long term impacts of offshoring on innovation because many other US industries are likely to adopt similar offshoring strategies.
\end{abstract}




\section{Introduction}

The term 'offshoring' has been applied to a number of established and emerging business practices. Most established offshoring practices involve the movement of low-skilled laborintensive manufacturing positions to other countries, especially in the developing world (Mills et al., 2004; Doh, 2005). Emerging business practices, enabled by advances in telecommunications and information technology, comprise offshoring of service positions, mostly to countries with large labor cost differentials (Slack and Lewis, 2002). Examples include remote operations of call centers and outsourcing of back-end management of software applications (Aron and Singh, 2005; Gopal et al., 2003).

Another emerging business practice of particular importance is offshoring of knowledge work such as research and development (Horvit, 2004). Examples include numerical analysis studies and software maintenance and development (Farrel, 2003). But firms are also offshoring high technology research work (e.g., The Economist, 2004; Tansey, 2004; Thibodeau and Lemon, 2004). For example, Intel recently increased its engineering workforce 150 percent by adding 600 engineers to its research and development operations in Russia (Foremski, 2004). A recent worldwide survey of 104 senior executives from a range of technology-driven industries conducted by the Economist Intelligence Unit (Borzo, 2004) found that 70\% of the respondents’ firms now employ R\&D talent abroad and 52\% plan to increase their investments in offshore research in the next three years. This trend is expected to continue (Venkatraman, 2004).

The fundamental argument for offshoring manufacturing, services or technological development is that optimizing global production will result in round-the-clock shifts and lower costs, which in turn will lead to expanded markets, lower prices for consumers, and the creation of new business opportunities for existing firms and new entry (Aron and Singh, 2005; Farrell, 
2005). Offshoring R\&D units can allow access to local knowledge not readily available at home, and can enable learning about complementary technologies (Dunning, 1995; Bartlett and Goshal, 1990; Hakanson, 1990; Florida, 1997; Zander, 2002). Doz et al. (2001) note that firms increasingly decide to locate their innovation effort wherever they believe the most propitious environment exists. Feenstra (1998) and Jaffee (2004) go even further, asserting that offshoring, like automation in the 1960s, is simply another innovative way to efficiently reallocate existing factors of production. To date, research on offshoring has focused mainly on its effect on both firm performance and the economic conditions of the regions or nations associated to the phenomenon. Company level assessments note that offshoring is a complex and often risky endeavor, but contend that, if done right, can have definite benefits for the firm (Aron and Singh, 2005; Barthelemy, 2003; Khong, 2005; Quinn, 1999, 2000). Existing macroeconomic studies suggest that offshoring low-skilled labor in areas such as manufacturing has a clear benefit for the home economy (Feenstra et al., 1999; Bardhan et al., 2004). More recent results on information technology and services also suggest that offshoring is beneficial to the firm as well as the home nation (Behravesh, 2004; Mann, 2003; Farrell, 2003). Researchers, corporate executives and policy makers thus conclude that offshoring will continue to benefit national home economies as long as displaced workers are absorbed into other positions where they will be able to generate greater value to the economy (Feenstra, 1998; Jaffee, 2004, Mankiw, 2004). Of course, the latter condition may not be satisfied in some regions or countries, such as Germany, where workers are less mobile (Farrell, 2004).

Previous research has also addressed ways in which offshoring affects innovation. The prevalent perspective is that offshoring either does not affect the innovative ability of the firm in its home location, or that it may actually help some efforts. This is because firms typically 
offshore non-core activities, providing more time for higher value-added activities such as innovation (Quinn, 2000; Chapman and Corso, 2005; Quelin and Duhamel, 2003). In addition, according to Quinn (1999), specialist suppliers to which the work is outsourced can find solutions that fragmented internal sources could never imagine - and they can implement those solutions rapidly without disruptive internal politics.

While the immediate and medium-term benefits of offshoring decisions are increasingly established, a less explored question relates to the long-term impact these decisions have on the home economy. Researchers have pointed out that even though many of the low-skill workers have been redeployed to high-tech occupations, we do not understand the long-term effects of offshoring on employment, wages, and technology innovation (Gomory and Baumol, 2000; Hira and Hira, 2005). Understanding the long-term effect of offshoring on technological innovation is of critical importance because innovation is increasingly recognized as the critical driver of economic growth (Romer, 1990; Baumol, 2002). Moreover, there is a looming concern within academics and the greater public that as manufacturing moves overseas, both engineering work and R\&D might follow, jeopardizing the ability of home economies to maintain their economic growth and leadership (Horvit, 2004; Hira and Hira, 2005).

Existing literature suggests that successful innovation happens through a delicate balance within a system that includes clients, suppliers, R\&D units, and the financial system (Lundvall, 1992; Edquist, 1997; Chapman and Corso, 2005; Mills et al., 2004). A similar view is defended by the literature on innovation clusters (Porter, 1990, 1998) and an emerging perspective that looks at a firm as part of an industrial ecology (Ricart et al., 2004). Thus, in light of such studies, our perspective is that significant offshoring movements have the potential to disrupt these systems and affect the ability of firms within the systems to innovate. 
To study such a critical issue, this paper analyzes how offshoring affects the rate of innovation that results from R\&D efforts conducted collectively by firms at their home location. This is in contrast to studying how offshoring affects the rate of innovation at offshore locations, or even at the individual firm level. The analysis explores the technology of rare-earth elements as a case study. Rare-earth technology is pertinent for three reasons: (1) new technologies in this area are highly associated with research and innovation activities (Wybourne, 2004), (2) the REE materials are used in a wide range of technology applications (Haxel et al., 2002), ranging from lasers to magnets and catalysts, and (3) the REE industry was an early adopter of offshoring practices, beginning in the 1990s, that affected the whole system involved in rare-earth technology innovation. In fact, the industry is among those that have evolved the furthest on this new path towards outsourcing and relocation away from the U.S. and towards developing countries (Haxel et al., 2002) This creates an excellent setting to study the potential longer term impacts of offshoring on innovation, especially in the home country.

Using patent data as a measure of innovative performance in REE technologies, we show that offshoring in material supply after 1990 is associated with a decline in the rate of US REE technology innovation. These results suggest a progressive loss of US REE technology innovation as elements of the innovation system are offshored. This conclusion is important at both firm and public policy levels. First, firms need to recognize that a strong offshoring trend in their business environment may have unintended negative impacts on the ability to innovate in their domestic market. This should lead them to incorporate contingencies in their development plans that deal with this situation, either by countering the trend or proactively adjusting to it. At the policy level, results show that offshoring benefits in reduced prices, expanded markets, or efficiency driven innovation, may come also with decreased innovation in certain areas, 
especially those closer to the activities that are being offshored. Further understanding of this trade-off is critical for a more comprehensive understanding of the impacts of offshoring at the level of the firm and overall economic development.

The paper is organized as follows. First, we discuss the literature used to frame hypotheses on the relation between offshoring and innovation. We then describe the REE material industry and include specific objectives of our empirical analysis related to offshoring. In the subsequent section, we explain the methods used for the quantitative study of patents showing the evolution of REE innovative activities. We then present the analysis of the patent data and discuss its implications. Finally, we draw conclusions from this analysis and suggest further work.

\section{Offshoring and Innovation: Firms, Systems and Ecologies}

According to Freeman (1987), a system of innovation is defined as the network of organizations within a common boundary whose activities and interactions initiate, import, modify and diffuse technologies. Several types of organizations comprise such a system. These include manufacturing firms, university research laboratories, government agencies including the patent office, suppliers of raw materials, and customer service firms (Edquist and Johnson, 1997; Merges and Nelson, 1990; Nelson, 1988). Successful innovation happens through a delicate balance within this system (Lundvall, 1992; Edquist, 1997). For example, results have shown that the innovation trajectory of an industry can be strongly conditioned by the role of upstream suppliers of materials and production equipment, and even those associated with their research equipment (Levin et al., 1987; Klevorick et al., 1995; Linder et al., 2005; Chapman and Corso, 2005). Likewise, innovation can also be affected by downstream entities, including professional and technical societies, independent inventors, and users of the industry's product (Levin et al., 1987; Hippel, 1988; Linder et al., 2005; Chapman and Corso, 2005). 
The recognition that firms' innovation dynamics happen by integrating knowledge and ideas from other organizations in the system suggests that removal of any one of these organizations may affect the innovation production within the system boundary. Such removal may be a direct result of the offshoring, such as a decision to locate or outsource research and development activities abroad, outside a national system boundary. It may also be an indirect result of removing knowledge, by offshoring manufacturing operations or services, thus separating relationships, and reducing technology interests within the system boundary. In fact, upstream suppliers and downstream users are critical sources of knowledge for technical advances of a set of firms, and often more important than established sources of knowledge such as universities or government laboratories (Klevorick et al., 1995; Council on Competitiveness, 2005).

The boundaries of an innovation system are commonly delimited by geographical dimensions. For example, a system of innovation can be 'national' as in the US national system of innovation (Freeman, 1987; Nelson, 1993; Lundvall, 1992). But it can also be 'regional' like Silicon Valley in California or Route 128 in Massachusetts, where such a regional setting enables researchers to explore the specific nature of the links between the various elements in the narrow environment (Cooke et al., 1997). Instead of using geographic dimensions, a system of innovation can be bounded by technology sectors as in a 'sectoral' or 'technological' system of innovation (Carlsson and Stankiewicz, 1995; Hughes, 1984; Callon, 1992; Malerba, 2002). These tighter definitions are important because some of the concerns on the potential adverse impacts that offshoring parts of the system has on innovation are particularly prevalent when proximity or interdependence matters.

The industrial cluster literature explores in detail these interdependence arguments for innovation also put forward by the innovation systems perspective, especially when regional 
proximity is an issue (Porter 1990, 1998). One of the drivers of competitiveness is the local availability of high-quality and specialized innovation inputs. These may include raw materials, trained scientists and engineers, or R\&D personnel. Cluster-specific R\&D productivity also depends on the local availability of R\&D personnel who are specialized in cluster-related disciplines. A second driver of competitiveness is the availability, density and interconnectedness of vertically and horizontally related industries in the region. Examples include raw material suppliers, specialized intermediate suppliers, original equipment manufacturers, and pre-competitive research and development institutions. If these networks are concentrated geographically, positive externalities from knowledge spillovers, transactional efficiencies, and cluster-level scale economies are greatly enhanced (Best, 2000; King et al., 2003; Kulmala and Uusi-Kauva, 2005). Thus, firms’ innovation strategies are most likely negatively affected by movement away from the geographic collocation of upstream suppliers and downstream users, The effect of offshoring on the region or nation may even be more pronounced if decreasing interest in the technology once championed by a set of firms causes universities to abandon any focus on the technology, reducing the availability of specific knowledge and human resources (Jenkins and Goodnick, 2004).

Recent literature on internationalization strategies, reviewed by Ricart et al. (2004), offers a complementary perspective to the innovation systems and clusters literature, but still with equivalent concerns on how offshoring might affect innovation over the long term. This perspective advances a view of the world as a dynamic ecology of locations and firms, where firm and industry diversity in a given geographic location matters, i.e., less diversity means less opportunity for technological innovation. In this view, a firm's decision to place individual activities in certain locations at particular times depends on the advantage of specific firm- and 
location-based resources and knowledge. This implies that firms are concerned about relocation of other firms active in technologies relevant to their industry. Firms are also responsive to changes in the breadth of R\&D activities in the regions where they are present, as all of these condition the local ecology and, as a consequence, the innovation potential of a firm-location pair.

Ricart et al. (2004) suggest that non-core services within a local ecological system are important for the generation of innovation in that location, such that offshoring firms may adversely affect the ecology of the home location by reducing important inputs for innovation in the long run. Nevertheless, it is important to note that, while the rate of innovation in a given location may decline with the removal of some of its elements, the same is not necessarily true for the rate of innovation of a focal offshoring firm. In fact, the contact with new offshore locations mean that new ecologies (or new systems, if one resorts to the literature previously discussed) become available to the focal firm, allowing for new and alternative innovation paths. If anything, existing literature suggests the process of innovation will improve as firms continue to leverage new and available pools of skilled labor (Quinn, 2000; Linder et al., 2005; Vanketraman, 2004).

As firms seek to position themselves in locations that maximize their efficiency and competitiveness, their decisions will be affected by the changing nature of the systems of innovation, industrial clusters and industrial ecology to which they are exposed. Unfortunately many firms participating in offshoring to increase their individual competitiveness are unwittingly responsible for changes in the system or ecology to which they belong. These alterations may negatively impact the innovative performance in their home base location. For example, an earlier study by Almeida (1996) found that, in the semiconductor manufacturing 
industry, foreign subsidiaries located in the particular US locations, in particular Silicon Valley, predominantly utilized knowledge developed in the US and contributed to local technological progress. But Macher and Mowery (2004) suggest that certain agglomeration effects that have sustained US dominance of R\&D employment in the semiconductor industry may weaken as the global geographic dispersion of semiconductor design and manufacturing activities grows.

Given this set of challenges, it is critical to empirically determine how firm-level offshoring decisions might affect the innovation processes in high technology industries in the US. We now use the REE industry as a case study to accomplish this.

\section{Rare Earth Elements, Offshoring and Innovation}

Rare-earth elements of the periodic table (see Table 1 below for a list of all these elements) have unique properties that make them valuable for a variety of high technology applications. For example, europium is uniquely employed as the red phosphor in computer monitors and televisions. Erbium is essential for fiber-optic telecommunication cables. High-strength rareearth magnets have allowed miniaturization of countless electronic components used in many consumer products, automobiles, communication systems, and military equipment. Rare-earth elements are also essential for copious catalysts employed in the chemical, petroleum and automotive industries (Haxel et al., 2002).

The US quickly became the dominant producer of REE raw materials after a high-grade deposit of REE ore found in Mountain Pass, CA was opened by Molycorp in the early 1950s. Molycorp invested millions of dollars in researching potential uses for REEs. As these elements became more abundant and research and development activities increased, their applications grew dramatically in diversity and importance. By 1965, this single deposit had become the most significant source of REEs in the world with reserves of 13 million metric tons. 
Mountain Pass was the dominant source of REEs from 1965 through the mid-1980s. This allowed a strong system of innovation to develop in the US supporting research and development on rare earths and the US consequently became the world leader in rare-earth technology innovation. But beginning in the mid-1980s, the firms began to locate components of their business outside of the strong US national system of innovation. For environmental and cost reasons firms began purchasing rare-earth materials from offshore providers leading to a significant change in the agents and firms they collaborated with regularly. First, the production of REEs in China increased dramatically (Figure 1), supplanting US production and encouraging firms to work with an offshore raw material supplier for lower cost materials. The shift in the supply base of the rare earth materials was critical because many rare-earth technology innovations were co-developed by US firms and their domestic material supplier. As production moved to Asia, cooperation between US firms and material suppliers was adversely affected; the geographic distance, culture differences, and time zone disparity hindered communication.

Second, China considered finely processed REE products as a priority for the nation (Lei, 1998), mobilizing resources and policies towards the development of the industry.

Insert Figure 1 about here

Chinese dominance of REE material production, their new emphasis on rare-earth technology, and lower-wage rates presented US firms with increased offshore competition. These developments led a number of US firms seeking to improve their individual competitiveness to offshore substantial operations to Asia. Moreover, these relocation decisions affected the quantity and location of R\&D activities of many firms. In fact, some firms 
responded by discontinuing significant portions of business activity reliant on rare earth elements. Today, Chinese mines produce about $95 \%$ of the world's supply of REEs, roughly 95,000 mt (USGS, 2005).

There are two prominent examples of how offshoring affected rare earth technology innovation processes in the US. First, the Rare-earth Information Center (RIC) based at Iowa State University closed in 2002 after financial support from industry and the University declined beginning in the early 1990s (Rare Earth, 2005). The RIC provided scientific and technical information concerning REEs to industry, government, and universities for more than 36 years. The second example is Magnequench, Inc., the technology leader in rare-earth magnet powder metallurgy that established a powder plant in Tianjin, China in 2000 and offshored their R\&D technology center from Research Triangle Park, North Carolina to Singapore in 2003. They cited geographic proximity to the source of raw materials and downstream users as the main reasons for their offshoring decisions (Magnequench, 2005).

Like the theory explored above, these examples seem to indicate that offshoring of REE supply can affect decisions of firms on where to locate production and innovation activities. The next step is then to empirically determine whether offshoring in the REE industry is indeed associated with changes in innovation preeminence of the US. Therefore, we propose two specific objectives:

1. To test if US rare earth innovation activity has decreased since the beginning of offshoring activities in the industry, and

2. To test if the propensity for the US to be a significant source of knowledge for rare-earth technology innovation has decreased since the beginning of offshoring activities. 
Note that the first objective specifically addresses innovation activities associated with rare earth elements. But even if the US has lost its leadership position in producing innovations in the rare earth industry, the country may still be the leading source of knowledge used in rare earth element innovation produced elsewhere. The second objective addresses the latter possibility.

The methods and data used for these objectives are described in the following section.

\section{Research Methodology}

This study uses patents issued by the United States Patent and Trademark Office (USPTO) over the period 1975 to 2004 as a proxy for rare-earth technology innovative activity. The analysis of such trends will be used to assess the innovative performance of US firms. There is a substantial prior body of literature arguing that patents are a useful measure of innovative activity (Campbell and Levine, 1984; Basberg, 1987; Acs et al., 2002). Although there are well documented limitations to the use of patent data, in particular the fact that not all innovations are patented, Griliches (1990) as well as Patel and Pavitt (1995) have documented that patents are a reasonable proxy for innovation especially in high technology industries. Archibugi and Pianta (1996) claim that patent data can provide estimates of innovative activity at the firm, industry, and country levels, while Pavitt (1985) concludes that patents provide a consistent picture of sectoral patterns of innovative activities. These claims make patent studies a useful measure for innovation within a system boundary and a good candidate to address the research questions highlighted above.

While many studies support the use of patents as a measure of innovation output, patent citations are also one of the most traceable records to understand critical knowledge flows (Jaffe et al., 1993, 2000; Stuart and Podolny, 1996; Mowery et al., 1996; Almeida, 1996). Citations are included in patent applications by the inventor and the patent examiner to help delimit the patent grant by identifying "prior art” of relevance to the focal patent. If one considers a given patent, 
citations by subsequent patents in particular firms or places can be used to indicate who is following up on the original invention, where work on the invention is being conducted and when they are doing so. Therefore, one can use citations to go beyond the innovative output information provided by granted patents to look at whether the role of the US as the focal point of knowledge generation for REE technology is changing over time.

But even if one accepts that patents are a reasonable indicator of changes in rare-earth technology innovation and that citations reflect changes in knowledge flows, we still might not be able to distinguish these changes from general patenting trends. For example, if we were to find that the share of patents resulting from R\&D activities in the US is declining over time, this may merely reflect the recent increase in foreign innovative activity resulting in application for US patents. Therefore, it is crucial to employ a control group. The ideal control group is one that requires similar methodology to build a patent benchmark dataset, would play a similar role to REE in a variety of high technology areas, and has maintained a stable material supply base over the relevant period of analysis. To fulfill these objectives, platinum group metal (PGM) technology is employed as the control group (see Table 1 below for a list of all these elements). Like REE, PGMs are essential for many high technology industries including the automotive, chemical, electronic, and petroleum refining industries. Figure 2 shows that the material production of PGMs has been shared by South Africa and Russia since 1950.

Insert Figure 2 about here

For the proposed study, three regression models using patent data are developed. Objective 1 is achieved through the first model that analyzes patent count trends resulting from US and 
foreign research over time, controlling in particular for the pre and post 1990 periods. Objective 2 is achieved through the second and third models that analyze the citations of the patents studied in the first model. All regressions have PGM as the control group.

\subsection{Patent Count Analysis}

\subsubsection{Data development}

The patent data were collected from the USPTO using an abstract-based search. The keywords for the search were the names of the relevant materials, both rare-earth and PGM (Table 1). The nature of this abstract-based keyword search captures both innovations resulting from the properties of the specified materials as well as innovations where the material is employed, but may not play a major role in the innovation. We would prefer to be able to isolate the innovations resulting from the properties of the specified material, but this was not possible due to the expanse of the patent data set. However, the nature of the compiled data set offers an overall unique perspective on rare-earth technology innovation. The patenting trends elicited from the data cover technology innovations produced directly from basic and applied rare-earth research as well as innovations in established technologies for which rare-earths are an essential component. As much as thirty-three very diverse patent classes are associated with REE patents. The critical information extracted from each patent included application date, assignee, country of assignee, country of origin (i.e., the first inventor's home location), and patent classification.

Insert Table 1 about here

Two methods were used to compile the complete dataset. First, for patents granted from 1975 to 1999, the National Bureau of Economic Research patent citations data file was employed 
(Hall et al., 2001). Second, for patents granted from 2000 to 2004, the critical information was manually downloaded from the full text patents available online at www.uspto.gov. The complete patent data set was 21,378 successful patents applied for from 1975 to 2001.

The active organization dataset was created by removing outlier organizations from the complete dataset. These were removed by sorting the complete patent dataset by assignee. All patents associated with an assignee that successfully applied for three or less patents were removed. This allowed the elimination of organizations that have only a minor innovation in the relevant technology and focus on those organizations that have a clear active participation in rare-earth or PGM innovation. Higher cut-off values were tried and they only marginally strengthen the results. The active organization dataset included 17,067 patents successfully applied for from 1975 to 2001. Figure 3 graphically displays the patent counts over time assigned to US and non-US organizations for rare-earth and platinum patents. It also displays the patent counts over time resulting from research conducted within and outside the US. It is visually evident from Figure 3 that the US is losing rare-earth technology leadership. The non-US locations that have seen consistent increases in rare-earth innovative activity (measured by patent counts) are Asia in general and Japan in particular. Increases in Asian rare-earth patenting activity began around 1990. Similarly, Asia and Japan, as well as Germany, have increased their patenting activity in technologies employing platinum group metals. Yet, while the visual trends suggest that our assertions of a potential loss of US innovation competitiveness may be associated with offshoring of materials and manufacturing, we need confirm these observations through statistical tests.

Insert Figure 3 about here 


\subsubsection{Dependent variable}

The dependent variable in the first regression analysis is a $0-1$ variable (USsite) with a value equal to 1 if the patent was applied for as a result of research conducted in the US. The site of the research is chosen over the home location of the organization assigned to each patent because we are most interested in exactly where the research is being conducted rather than which organization is directing the research. If a decreasing trend is found for the dependent variable, it suggests that the US is no longer the most profitable location for conducting rare-earth innovation activity. This could result from the possibility that the most propitious environment for conducting research is now no longer located in the US or rare-earth innovation activity is itself declining. It is evident from Figure 3 that total rare-earth innovation activity is increasing.

\subsubsection{Model and critical variables}

The purpose of the analysis is to determine if there is a significant downward trend in the propensity for REE innovative activities to be conducted within the US. To perform this evaluation, three controls are of critical importance. The first $(A P Y R)$ is a linear trend variable employed to capture overall time effects in the propensity for US research to result in successful patent applications in these technologies. The second is a $0-1$ variable (REPat) that is employed to control for the overall propensity difference between rare-earth patents and the PGM patents benchmark group. An additional 0-1 variable $\left(d_{1}\right)$ is also utilized to capture any significant change in the propensity trends before and after a chosen year. For the proposed analysis, the year of interest is 1990, which corresponds to the beginning of Chinese dominance in the production of rare-earth materials. The results are not sensitive to minor changes in the year of 
interest. Summary statistics for the variables of various datasets used in the analysis are presented in Table 2. We denote the active organization dataset as Model 1, the Top 100 dataset as Model 2, and the complete dataset as Model 3. The Top 100 dataset is limited to the top 100 REE and PGM organizations in terms of number of patents to try to isolate the trend among the heavy innovators in the industry. It is important to note that the descriptive statistics of the variables are similar in all three models.

Insert Table 2 about here

A probit model is used to estimate the impact of the interaction variables on the propensity for a successfully applied patent to be the result of US research. A logit model was also employed and the results were found to be similar. In Model $1 a$ we test for a significantly different trend in the propensity for a rare-earth patent to be the result of US research after 1990, when compared to the PGM benchmark. Two interactions are included in the model, (APYR*REPat) and $\left(d_{1}^{*} A P Y R^{*} R E P a t\right)$. The first interaction calculates the difference in the overall propensity trend for rare-earth patents. The second determines if there is a significant change in this propensity trend after 1990.

Model $1 a$ is specified in the following form:

$$
\begin{aligned}
\operatorname{Pr} o b(\text { USsite }=1)=F\{ & +\beta R E P a t+\delta_{1} A P Y R+ \\
& \left.+\lambda_{1}(\text { APYR } * \text { REPat })+\lambda_{2} d_{1}(\text { APYR } * R E P a t)+\varepsilon\right\}
\end{aligned}
$$

where $\operatorname{Prob}(U S s i t e=1)$ is the probability that a successfully applied patent is the result of domestic research. $\mathrm{F}\{$.$\} is the cumulative normal distribution. We expect to find the coefficient$ of the second interaction term, $\lambda_{2}$, to be negative (i.e., decreasing propensity for rare-earth innovation activity to be conducted within the US after 1990). 
To ensure that the result is robust, we conduct a second run (Model 1b) that controls for the possibility that there is a change in overall patents trends after 1990 by including a third interaction $\left(d_{1} * A P Y R\right)$.

Model $1 b$ is specified in the following form:

$$
\begin{aligned}
\operatorname{Pr} o b(\text { USsite }=1)=F\{\alpha & +\beta R E P a t+\delta_{1} A P Y R+\delta_{2} d_{1} A P Y R \\
& \left.+\lambda_{1}\left(A P Y R^{*} \text { REPat }\right)+\lambda_{2} d_{1}\left(A P Y R^{*} R E P a t\right)+\varepsilon\right\}
\end{aligned}
$$

We expect to find that $\lambda_{2}$, the coefficient of the $\left(d_{1} * A P Y R^{*} R E P a t\right)$ interaction term, will remain negative.

\subsection{Patent Citation Analysis}

\subsubsection{Data development}

The active patent dataset previously described was further developed by acquiring the relevant citations for each patent. For the purpose of this analysis, the relevant citations were those patents already contained in the complete dataset previously described, ignoring all the rest. The idea is to capture pertinent knowledge transfers within the relevant material technologies. The critical information extracted from each citation was the application year, country of the assignee, and the first inventor's home location. Since we are concerned with knowledge transfers between organizations and not within organizations, self (i.e., same assignee) citations were also not considered. The resulting dataset was then limited to successful patent applications from 1982 to 1997. Since the analysis is concerned with recent knowledge generation and transfers, citations of patents applied for more than seven years prior to the citing patent application year were omitted from the citation patent dataset. The results are not sensitive to minor changes in the cutoff year. A cutoff of seven years includes 63 percent of all citations and was also chosen to avoid data truncation problems. Since our citation dataset is drawn from 
the original patent dataset covering the years 1975 to 2001, citations for a patent applied for in 1978 would have only three prior years of patents from which to draw. However, a patent applied for in 1995 would have 20 prior years of patents from which to draw. Therefore, by limiting the citation lag to seven years, all patents included in the citation dataset have an equal number of years from which to draw citations. The citation patent dataset included 8,289 citations from 4,168 patents.

\subsubsection{Dependent variable}

The dependent variable in the citation regression analyses was a 0-1 variable (CitedUSsite), with a value equal to 1 if the cited patent was the result of research conducted in the US. This variable captures the propensity for prior knowledge used for innovative activities to originate within the US. If a decreasing trend is found for the dependent variable, it suggests an erosion of US leadership in rare-earth technological innovation.

\subsubsection{Model and critical variables}

The purpose of the citation analysis is to determine if the US is losing leadership as the knowledge source utilized by organizations for rare-earth innovative activities. Therefore, a 0-1 variable (REPat) is employed to control for the overall propensity for a rare-earth patent to cite a prior patent generated by US research relative to the platinum benchmark group. Another 0-1 variable (CitingUSsite) is employed to control for whether the citing patent was the result of research conducted in the US. It is plausible to assume that innovation activity conducted within the US has a greater propensity for citing prior patents also generated by US research. Like the previous analysis, an additional 0-1 variable $\left(d_{1}\right)$ is employed to capture a significant change in the propensity trends before and after 1990. The results are not sensitive to minor changes in the 
year of interest. The critical variable for the analysis is again the application year for each patent (CitingAPYR). Summary statistics for the variables used in the analysis are presented in Table 3.

Insert Table 3 about here

Two clustered error probit models, Models 4 and 5, are used to estimate the impact of the interaction parameters on the propensity of knowledge sources for new innovative activity to originate within the US. We conducted clustered regressions in order to relax the assumption of independence of citations within a given focal patent. Running clustered regressions implicitly uses robust (i.e. “correct”) standard errors, even if the observations are correlated within each focal patent. In Model 4a, we test for a US citation trend difference after 1990 between rare-earth and platinum patents. Two interactions are included in the model, (CitingAPYR*REPat) and $\left(d_{1} *\right.$ CitingAPYR*REPat). The first interaction calculates the difference in the overall propensity trend for rare-earth patents to cite patents generated by US research compared to the benchmark platinum patents. The second determines if there is a significant change in this propensity trend after 1990.

Model $4 a$ is specified in the following form:

$$
\begin{aligned}
\operatorname{Pr} o b(\text { CitedUSsite }=1)=F\{\alpha & +\beta \text { CitingUSsite }+\gamma R E P a t+\delta_{1} \text { CitingAPYR }+ \\
& \left.+\lambda_{1}(\text { CitingAPYR* REPat })+\lambda_{2} d_{1}(\text { CitingAPYR* REPat })\right\}
\end{aligned}
$$

where Prob(CitedUSsite $=1$ ) is the probability that a successfully applied patent cites a prior patent that was generated by US innovation activity. $\mathrm{F}\{$.$\} is the cumulative normal distribution.$ We expect to find the coefficient of the second interaction term, $\lambda_{2}$, to be negative (i.e., decreasing propensity for the US to be a knowledge source for rare-earth innovative activities after 1990). 
To ensure that the result is robust, we conduct a second run (Model $4 b$ ) that controls for the possibility that there is a change in the overall propensity for patents to cite patents generated by US research after 1990 by including a third interaction $\left(d_{1} *\right.$ CitingAPYR).

Model $4 b$ is specified in the following form:

$$
\begin{aligned}
\operatorname{Pr} o b(\text { CitedUSsite }=1)=F\{\alpha & +\beta \text { CitingUSsite }+\gamma R E P a t+\delta_{1} \text { CitingAPYR }+\delta_{2} d_{1} \text { CitingAPYR } \\
& \left.+\lambda_{1}(\text { CitingAPYR } * \text { REPat })+\lambda_{2} d_{1}(\text { CitingAPYR } * \text { REPat })\right\}
\end{aligned}
$$

We expect to find that $\lambda_{2}$, the coefficient of the $\left(d_{1}{ }^{*}\right.$ CitingAPYR*REPat $)$ interaction term, will remain negative.

Model 5 is employed to determine if there is an identifiable trend for domestic research activities among the group. It tests whether rare-earth innovation activity conducted within the US has shown a decreasing propensity to utilize domestic knowledge sources after 1990 when compared to the PGM benchmark. First in Model 5a, we test for a significantly different trend in the propensity for rare-earth patents generated by US research to cite a prior patent that resulted from research conducted in the US. Three interaction parameters are included in the model, (CitingAPYR*CitingUSsite), (CitingAPYR*CitingUSsite*REPat), and $\left(d_{1} *\right.$ CitingAPYR*CitingUSsite $\left.* R E P a t\right)$. The first interaction term calculates the overall propensity trend for US innovation activity to utilize "prior art” generated domestically. The second calculates the overall propensity trend for REE innovative activity conducted within the US to utilize "prior art” generated domestically. The third determines if there is a significant change in this propensity after 1990.

Model $5 a$ is specified in the following form:

$$
\begin{aligned}
\text { Pr ob }(\text { CitedUSsite }=1)=F\{ & +\beta \text { CitingUSsite }+\gamma R E P a t+\delta \text { CitingAPYR } \\
& +\lambda_{1}(\text { CitingAPYR } * \text { CitingUSsite })+ \\
& +v_{1}(\text { CitingAPYR* CitingUSsite } * \text { REPat })+ \\
& \left.+v_{2} d_{1}(\text { CitingAPYR } * \text { CitingUSsite } * \text { REPat })+\varepsilon\right\}
\end{aligned}
$$


where Prob(CitedUSsite $=1$ ) is the probability that a successfully applied patent cites a prior patent that was generated by US innovation activity. F\{.\} remains the cumulative normal distribution. We again expect that the coefficient of the third interaction term, $v_{2}$, to be negative (i.e., rare-earth innovation activity conducted in the US is less likely to depend on other research conducted with the US as a knowledge source for their innovative activities after 1990).

We conduct a second run (Model 5b) that controls for the possibility that there is a change in the overall propensity for US organizations to cite US patents after 1990. We implement this by including a fourth interaction $\left(d_{1}{ }^{*}\right.$ CitingAPYR*CitingUSsite).

Model $5 b$ is specified in the following form:

$$
\begin{aligned}
\operatorname{Pr} o b(\text { CitedUSsite }=1) & =F\{\alpha+\beta \text { CitingUSsite }+\gamma R E P a t+\delta \text { CitingAPYR } \\
& +\lambda_{1}\left(\text { CitingAPYR }{ }^{*} \text { CitingUSsite }\right)+\lambda_{1} d_{1}(\text { CitingAPYR* CitingUSsite })+ \\
& +v_{1}\left(\text { CitingAPYR }{ }^{*} \text { CitingUSsite } * \text { REPat }\right)+ \\
& \left.+v_{2} d_{1}\left(\text { CitingAPYR }{ }^{*} \text { CitingUSsite* }{ }^{*} E P a t\right)+\varepsilon\right\}
\end{aligned}
$$

We expect to find that $v_{2}$, the coefficient of the $\left(d_{1}{ }^{*}\right.$ CitingAPYR*CitingUSsite*REPat) interaction term will remain negative.

\section{Results and Discussion}

\subsection{Critical results}

Table 4 shows the regression results of the patent count analysis using each dataset. Results from the active organizations dataset (Model 1), Top 100 dataset (Model 2), and complete dataset (Model 3) confirm that the US is losing leadership in rare-earth innovation. The first important outcome in Model $1 a$ is that the coefficient for application year (APYR) is negative $(-0.03, \mathrm{p}<$ 0.001), indicating that the share of research activity conducted within the US resulting in successfully applied rare-earth and platinum patents is decreasing over the study time period. 
This result may just reflect the overall globalization of innovation activity. Moreover, the trend for REE over the entire period, measured through the coefficient on (APYR*REPat), suggests that rare-earth innovative activity is globalizing at a faster rate $(-0.01, \mathrm{p}<0.01)$. But when one isolates the specific REE patenting trend after 1990, through the $\left(d_{1}^{*} A P Y R * R E P a t\right)$ interaction term, the corresponding coefficient is also negative and significant $(-0.02, \mathrm{p}<0.01)$. In other words, for each additional year after 1990, US research results in the application of $1 \%$ less REE patents compared to the PGM trend. This suggests that since a viable source of REE raw material became available offshore, the propensity for successful rare-earth patents to have resulted from US research is decreasing even faster. These relationships become stronger if we control for the possibility that the overall patenting trend changes after 1990. For example, this is shown in the Model $1 b$ coefficient results for the $\left(d_{1} * A P Y R^{*} R E P a t\right)$ interaction parameter $(-0.05, \mathrm{p}<0.001)$. The above coefficients for the three interactions are even greater in magnitude if the dataset is limited to patents assigned to the top 100 organizations as in Models $2 a$ and $2 b$.

Insert Table 4 about here

Table 5 shows the regression results of the citation analysis using the citation patent dataset for the two models. Results confirm that the likelihood for the US to be a knowledge source for rare-earth innovative activities, especially those conducted within the US, is decreasing. First, for Models $4 a$ and $4 b$, the coefficients for the application year variable (CitingAPYR) are negative (0.02, $\mathrm{p}<0.001$ and $-0.03, \mathrm{p}<0.01$ ). This indicates that the tendency for the US to be a knowledge source for rare-earth and PGM innovative activities is decreasing over the study time period. Further, the coefficients for interactions No. 2 and 3 in Model $4 a$ fail to show a 
statistically significant difference in this trend for rare-earth patents before or after 1990 . However, when controlling for the possibility of an overall change in the patent citations trend after 1990, through interaction No. 1 in Model 4b, the coefficient for interaction No. 3 $\left(d_{1} *\right.$ CitingAPYR*REPat $)$ remains negative and becomes marginally significant $(-0.05, \mathrm{p}<0.10)$. The coefficient for interaction No. $2\left(d_{1}{ }^{*}\right.$ CitingAPYR*REPat $)$ also becomes marginally significant. This suggests that the propensity for the US to be a knowledge source for REE innovative activities has been decreasing at a faster rate since a viable source of REE raw material became available offshore.

Insert Table 5 about here

Second, for Models $5 a$ and $5 b$, the coefficients for the application year variable (CitingAPYR) are negative and comparable in magnitude to the coefficients in Models $4 a$ and $4 b$, but somewhat less significant. The variance in the dependent variable (CitedUSsite), previously almost exclusively explained by CitingAPYR, is now explained by interactions No. 4 and 6-7 included in Models $5 a$ and $5 b$. The coefficient for interaction No. 4 (CitingAPYR*CitingUSsite) is negative $(-0.01, \mathrm{p}<0.10)$, indicating that innovation activity conducted in the US is increasingly exploiting knowledge generated abroad. The coefficient for interaction No. 6 (CitingAPYR*CitingUSsite*REPat) is positive $(0.04, \mathrm{p}<0.001)$, indicating that organizations conducting REE innovative activity within the US were increasingly dependent on domestic knowledge as we move backward in time starting in 1990. Consistent with this trend, the coefficient for interaction No. $7\left(d_{1}{ }^{*}\right.$ CitingAPYR ${ }^{*}$ CitingUSsite ${ }^{*}$ REPat $)$ in Model $5 a$ is negative but insignificant, signifying that after a viable source of REE raw material became available 
offshore, US rare-earth innovative activities may have been decreasingly dependent on domestic knowledge. If we control for a change in the propensity trend after 1990 for research conducted within the US to cite domestic knowledge by including interaction No. 5 $\left(d_{1}{ }^{*}\right.$ CitingAPYR*CitingUSsite) in Model 5b, the coefficients for the interactions No. 4, 6-7 increase in magnitude. Most importantly, the coefficient for interaction No. 7 $\left(d_{1} *\right.$ CitingAPYR $*$ CitingUSsite*REPat $)$ remains negative and becomes significant $(-0.07, \mathrm{p}<$ 0.05). These results confirm that organizations active in rare-earth innovation activity within the US are employing domestic knowledge at a decreasing rate.

\subsection{Interpreting the results}

Overall, regression results suggest that US leadership in REE technology innovation is eroding. This loss in US REE technology innovation leadership is significantly correlated with the offshoring of material supplies, even when controlling for alternative explanations. As described before, existing literature suggests that local suppliers play a unique and critical role in supporting technological change in an innovation system - or ecological - system (Klevorick et al., 1995; Ricart et al., 2004). The results provide evidence supporting this notion that offshoring components of this system is associated with decreases in the aggregate rate of innovation in the home location. Nevertheless, it is important to note that results do not provide indications as to whether firms active in rare earth technology innovation increased or decreased their individual rate of innovation.

Firms that produce rare-earth permanent magnets in the US are a good example of the trend identified in the regression study. Permanent magnets are dominated by two rare-earth materials, samarium-cobalt (SmCo) and neodymium-iron-boron (NdFeB). Since 1990, four US permanent magnet manufacturers have discontinued their US operations. Consequently, most multinational 
enterprises active in the production of $\mathrm{NdFeB}$ magnets now maintain only sales operations in the US. Meanwhile, the Chinese share of NdFeB magnet production increased from $14.4 \%$ in 1988 to nearly 40\% in 1997 (Dongpei and Qiming, 1999). Trout (2002) suggests that the powerful combination of locally available rare-earths, inexpensive labor and a desire to make value added products has led to a large percentage of rare-earth magnets and products containing magnets being exported from China. The current trend indicates most magnet production will leave the US within the next decade, in favor of low labor cost regions, predominantly China (Trout, 2002). Such trends have quickly altered the system of organizations in the US producing and supporting permanent magnet products and innovation.

Informal conversations with one firm representative revealed that removing manufacturing from the US has also led to the removal of over $90 \%$ of domestic R\&D activities on rare-earth permanent magnet materials. More importantly, the knowledge for producing NdFeB magnets within the US has been lost. US based manufacturers can no longer compete with the quality of NdFeB magnets produced in China or Japan. This is analogous to the comparative advantage shift suggested by Gomory and Baumol (2000). Likewise, Magnequench, Inc., the top producer of neodymium magnetic powders and magnets and leader in innovation in the NdFeB magnet market, has responded to these significant changes by selling their US permanent magnet manufacturing operations and moving their R\&D facilities to Singapore (Magnequench, 2005).

These anecdotal developments are in line with the results highlighted above, which indicate that the US may no longer provide the most propitious environment to locate innovative activity for rare-earth permanent magnets. They lend support to some of the concerns of researchers and the public. As Hira and Hira (2005: Page 117) note “[...] from a technological innovation point of view, manufacturing matters greatly. Nearly 41 percent of American engineers work in the 
manufacturing sector. The manufacturing sector also accounts for 62 percent of all research and development (R\&D) and 90 percent of all patents in the U.S. The prevailing management approach is to locate $\mathrm{R} \& \mathrm{D}$ as close to manufacturing production as possible. As manufacturing moves overseas, it is inevitable that both engineering work and R\&D will follow.”

\section{Conclusions, implications, and future research direction}

This research looks at the evolution of innovation in high technology that employs rare-earth materials. Since 1975, there has been a progressive offshoring of critical components of organizations active in rare earth technology. In particular, starting in 1990, China emerged as the dominant producer of REE materials, completely supplanting US production, and a significant portion of manufacturing operations employing REEs has been offshored to Asia. These outcomes have significantly affected rare-earth innovation processes in the US.

Using patents as a proxy for rare-earth innovative activity, this study shows that the US is losing its longstanding leadership in many areas of rare-earth technology. Not only is the rate of successful rare-earth patent applications by US organizations decreasing in relation to the rest of the world, but the likelihood that knowledge generated in the US will be used for such innovative activity is also decreasing. The results support the theories suggesting that offshoring elements of a system relevant for technology innovation may reduce the level of R\&D and productivity of innovation processes at the home location. When this is the case, one might expect such offshoring activities to weaken US technology innovation leadership over the long-term.

Looking at this recent evolution of high technology that employs REE materials is extremely relevant because other US technology industries are likely to adopt similar strategies. The US is also thought to be at risk for losing technology leadership in areas such as steel, heavy industrial manufacturing, and commercial aircraft industry. Although the reasons for these risks are 
diverse, offshoring plays critical roles in each of these industries. For example, Pritchard and MacPherson (2004) find that internationalizing the manufacturing and design processes, mainly through offshoring, may soon compromise the ability of the US to impact the manufacturing side of the commercial aircraft industry.

In face of these conclusions, important business and public policy challenges arise. First, when making offshoring decisions, firms need to evaluate how their innovation dynamics will be affected, especially in their home base. Existing studies have highlighted how offshoring will affect the operational context of the home base and the need to carefully consider what processes to offshore as a function of this risk (Aron and Singh, 2005). The results of this paper indicate that firms need to look beyond operations and question also how innovation might be affected by offshoring. While offshoring may bring innovation opportunities (Quinn, 1999), especially through the contact and interaction with new locations and partners (Ricart et al., 2004), it also brings risks that firms need to evaluate and act upon. In addition, the findings of this research offer a complementary view to the perspective of Chapman and Corso (2005), which assert the need for firms to increasingly plan their innovation within a collaborative supply chain environment. While their discussion focuses mostly on the inter-firm relations, our results suggest that firms need to also consider partner location in the collaborative equation.

Second, while most public policy discussion on offshoring has been related to jobs and wages (Doh, 2005), the results of this paper show that it is important to question important perspectives on innovation dynamics and policy. For example, it has been widely recognized that some of the most important public policies for shaping a nation's level of innovative capacity are those encouraging investment in science and engineering (Furman et al., 2002).Yet, the offshoring practices of many firms could lead one to question public support for basic research 
because of the difficulty and uncertainty of appropriating a majority of the benefits nationally (Archibugi et al., 1999). This may be further aggravated because offshoring practices may be replacing human capital investment in science and engineering as the go-to business practice for knowledge generation and technology innovation (Hira and Hira, 2005). While it is clear that protectionist public policies to prevent offshoring only weaken the global competitiveness of the US, it is critical to reflect on the role of public policy in a business environment where offshoring practices may lead, not only to job losses, but also a decline in innovation for certain areas.

Policies are likely to cluster in two extremes. On the one hand, just like facilitating the transition of workers displaced by offshoring decisions to other areas, policies may need to support quick redeployment of resources from areas of innovation that decline as a result of offshoring into new and more promising work. In the opposite extreme, the government may need to provide support to areas subject to market failure in terms of national private R\&D investment because of offshoring decisions, because the existence of local knowledge is considered relevant for the innovation dynamics of the region or nation. Yet, our understanding of these issues is still very limited and further work on how these policies affect a firm's location and offshoring decisions is needed before implementing appropriate public policies to support and sustain US innovation competitiveness. In particular, it is reasonable to expect offshoring decisions not to pose risks to innovation in all cases and every situation. Therefore, it is crucial for subsequent research to further explore this issue in more detail.

For the current study, we relied on theories and analysis at a systems level, reaching the conclusion that offshoring may affect innovation processes within the boundary of a system, such as a nation. However, offshoring decisions are fundamentally firm-level decisions. This means analyses that focus on a national, regional, or industry level will give us a collective 
perspective of a critical issue, but will still fail to capture important instances and traces related to individual firm realities and decisions. In future work we aim to explore the concept of an 'immediate system of innovation'. This concept aims to bring the perspectives of the systems of innovation, innovation clusters and ecology literatures to the individual firm level of analysis. This will allow the development of a conceptual firm level perspective to guide specific hypotheses as to how changes in the firm 'immediate innovation system' due to offshoring decisions might condition its innovation ability and performance. Our future empirical analysis will then analyze firm-level rare-earth technology innovation activities before and after each firm chooses to switch from the US rare earth raw material provider to an offshore provider. We expect to document the relative importance of organizations, relationships and processes to a firm's innovation ability and how to best respond to changes induced by offshoring.

\section{ACKNOWLEDGMENTS}

The authors would like to thank Mitchell Small and Pedro Oliveira for their constructive suggestions during the development of this research. The peer review comments of two anonymous reviewers are also greatly appreciated. This project was supported by a grant from the Pennsylvania Infrastructure Technology Alliance, financial assistance from INMETCO, Inc., and funding from the NSF Division of Social and Economic Sciences grant SES-0451096. 


\section{REFERENCES}

Acs, Z., Anselin, L., Varga, A., 2002. Patents and innovation counts as measures of regional production of new knowledge. Research Policy 31, 1069-1085.

Almeida, P., 1996. Knowledge sourcing by foreign multinationals: Patent citation analysis in the US semiconductor industry. Strategic Management Journal 17, 155-165.

Archibugi, D., Howells, J., Michie, J., 1999. Innovation Systems in a Global Economy. Technology Analysis and Strategic Management 11 (4), 527-539.

Archibugi, D., Pianta, M., 1996. Measuring technological change through patents and innovation surveys. Technovation 16 (9), 451-468.

Aron, R., Singh, J., 2005. Getting offshoring right. Harvard Business Review 83, 135-147.

Bardhan, A., Jaffee, D., Kroll, C., 2004. Globalization and a High-Tech Economy : California, the United States and Beyond, Kluwer, Boston, MA.

Barthelemy, J., 2003. The seven deadly sins of outsourcing. Acadmemy of Management Executive 17 (2), 87-99.

Bartlett, C., Goshal, S., 1990. Managing innovation in the transnational corporation. In: Bartlett, C., Doz, Y., Hedlund, G. (Eds)., Managing the global firm, Routledge, London, pp. .

Basberg, B., 1987. Patents and the measurement of technological change: A survey of the literature. Research Policy 16, 131-141.

Baumol, W., 2002. The Free-Market Innovation Machine: Analyzing the Growth Miracle of Capitalism. Princeton University Press, Princeton, NJ.

Behravesh, N., 2004. The comprehensive impact of offshore software and IT services outsourcing on the U.S. economy and the IT industry. Global Insight (USA), Inc., Lexington, MA. 
Best, M., 2000. Silicon Valley and the resurgence of Route 128: Systems integration and regional innovation. In: Dunning, J. (Ed.)., Regions, globalization, and the knowledge-based economy, Oxford University Press, Oxford, pp. 459-484.

Borzo, J., 2004. Scattering the seeds of invention: The globalization of research and development. The Economist Intelligence Unit.

Callon, M., 1992. The dynamics of techno-economic networks. In: Coombs, R., Walsh, V. (Eds)., Technical change and company strategies: Economic and sociological perspectives, Harcourt Brace Jovanovich Publishers, San Diego, pp. 72-102.

Campbell, R., Levine, L., 1984. Technology indicators based on patent/citation? Data: Three case studies. Battelle Pacific Northwest Laboratory, Richland, WA.

Carlsson, B., Stankiewicz, R., 1995. On the nature, function and composition of technological systems. In: Carlsson, B. (Ed)., Technological systems and economic performance: The case of factory automation, Kluwer Academic Publishers, Dordrecht, pp. 21-56.

Chapman, R., Corso, M., 2005. From continuous improvement to collaborative innovation: the next challenge in supply chain management. Production Planning \& Control 16(4), 339-344.

Cooke, P., Uranga, M., Extebarria, E., 1997. Regional innovation systems: institutional and organizational dimensions. Research Policy 4/5, 475-491.

Council on Competitiveness, 2005. National Innovation Survey, http://innovateamerica.org/download/2005_National_Innovation_Survey.pdf.

Doh, J., 2005. Offshore outsourcing: Implications international business and strategic management theory and practice. Journal of Management Studies 42(3), 695-704.

Dongpei, L., Qiming, Y., 1999. Research and development of rare earth permanent magnets in China. Rare Metals 18(3), 235-240. 
Doz, Y., Santos, J., Williamson, P., 2001. From global to metanational: How companies win in the knowledge economy. Harvard Business School Press, Boston, MA.

Dunning, J., 1995. Reappraising the eclectic paradigm in an age of alliance capitalism. Journal of International Business Studies 26, 461-491.

The Economist., 2004. India's growing strength in innovation. The Economist.

Edquist, C., Johnson, B., 1997. Institutions and organizations in systems of innovation. In:

Edquist, C., (Ed)., Systems of innovation: Technologies, institutions and organizations,

Pinter Publishers, London, pp. 41-63.

Edquist, C., 1997. Systems of innovation: Technologies, institutions and organizations. Pinter Publishers, London.

Farrell, D., 2003. Offshoring: Is it a win-win game? McKinsey Global Institute.

Farrell, D., 2004. Can Germany win from offshoring? McKinsey Global Institute.

Farrell, D., 2005. Offshoring: Value creation through economic change. Journal of Management Studies 42, 675-683.

Feenstra, R., 1998. Integration of trade and disintegration of production in the global economy. Journal of Economic Perspectives 12 (4),.31-50.

Feenstra, R., Hanson, G., Swenson, D., 1999. Offshore assembly from the United States:

Production characteristics of the 9802 program.

Florida, R., 1997. The globalization of R\&D: Results of a survey of foreign-affiliated R\&D laboratories in the USA. Research Policy 26, 85-103.

Foremski, T., 2004. Intel looks to Russia to build R\&D. The Financial Times.

Freeman, C., 1987. Technology policy and economic performance: Lessons from Japan. Pinter Publishers, London. 
Furman, J., Porter, M., Stern, S., 2002. The determinants of national innovative capacity. Research Policy 31 (6), 899-933.

Gomory, R., Baumol, W., 2000. Trade and conflicting national interests. MIT Press, Cambridge, MA.

Gopal, A., Sivaramakrishnan, K., Krishnan, M.S., Mukhopadhyay, T., 2003. Contracts in offshore software development: An empirical analysis. Management Science 49 (12), 16711683.

Griliches, Z., 1990. Patent statistics as economic indicators: A survey. Journal of Economic Literature 28 (4), 1661-1707.

Hakanson, L., 1990. International decentralization of R\&D - the organizational changes. In: Bartlett, C., Doz, Y., Hedlund, G., (Eds)., Managing the Global Firm, Routledge, London, UK.

Hall, B., Jaffe, A., Tratienberg, M., 2001. The NBER Patent Citation Data File: Lessons, Insights and Methodological Tools. NBER Working Paper 8498.

Haxel, G., Hedrick, J., Orris, G., 2002. Rare earth elements - Critical resources for high technology. United States Geological Survey FS-087-02.

Hippel, E.v., 1988. The sources of innovation. Oxford University Press, New York, NY.

Hira, R., Hira, A., 2005. Outsourcing America: What's behind our national crisis and how can we reclaim American jobs. AMACOM, New York, NY.

Horvit, M., 2004. Delphi Among Firms Sending Engineering, Research Work Out of U.S. Fort Worth Star-Telegram. 
Hughes, T., 1984. The evolution of large technological systems. In: Bijker, W., Hughes, T., Pinch, T., (Eds)., The social construction of technological systems: New directions in the sociology and history of technology, MIT Press, Cambridge, MA, pp. 51-82.

Jaffe, A., Trajtenberg, M., Henderson, R., 1993. Geographic localization of knowledge spillovers as evidenced by patent citations. Quarterly Journal of Economics 108 (3), 577-598.

Jaffe, A., Trajtenberg, M., Fogarty, M., 2000. Knowledge spillovers and patent citations: Evidence from a survey of inventors. American Economic Review 90 (2), 215-218. Jaffee, D., 2004. Globalization, offshoring, and economic convergence: a synthesis. Understanding Global Outsourcing Conference, New York.

Jenkins, K., Goodnick, S., 2004. Globalization and workforce training in Electrical and Engineering Education. The Interface, IEEE Education Society.

Khong, K., 2005. The perceived impact of successful outsourcing on customer service management. Supply Chain Management-an International Journal 10 (5), 402-411.

King, C., Silk, A., Ketelhohn, N., 2003. Knowledge spillovers and growth in the disagglomeration of the US advertising-agency industry. Journal of Economics \& Management Strategy 12, 327-362.

Klevorick, A., Levin, R., Nelson, R., Winter, S., 1995. On the sources and significance of interindustry differences in technological opportunities. Research Policy 24, 185-205.

Kulmala, H., Uusi-Kauva, E., 2005. Network as a business environment: experiences from software industry. Supply Chain Management-an International Journal 10 (3), 169-178.

Lei, X., 1998. China: 15 new projects bolster basic research. Science 282 (5397), 2171-2171.

Levin, R., Klevorick, A., Nelson, R., Winter, S., 1987. Appropriating the returns from industrial R\&D. Brookings Papers on Economic Activity (3), 783-820. 
Linder, J., Jarvenpaa, S., Davenport, T., 2005. Toward an innovation sourcing strategy. MIT Sloan Management Review 44 (4), 43-49.

Lundvall, B., 1992. National systems of innovation: Towards a theory of innovation and interactive learning. Pinter Publishers, London.

Macher, J., Mowery, D., 2004. Vertical specialization and industry structure in high technology industries. Business Strategy over the Industry Life Cycle Advances in Strategic Management: A Research Annual 21, 317-355.

Magnequench, 2005. http://www.magnequench.com/mag_news/index.htm.

Malerba, F., 2002. Sectoral systems of innovation and production. Research Policy 31, 247-264.

Mankiw, N.G., 2004. The Economic Report of the President. Washington DC, Council of Economic Advisors. February 17, 2004.

Mann, C., 2003. Globalization of IT services and white collar Jobs: The next wave of productivity growth. Institute for International Economics, PB03-11.

Merges, R., Nelson, R., 1990. On the complex economics of patent scope. Columbia Law Review 90 (4), 839-916.

Mills, J., Schmitz, J., Frizelle, G., 2004. A strategic review of “supply networks”. International Journal of Operations \& Production Management 24(10), 1012-1036.

Mowery, D., Oxley, J., Silverman, B., 1996. Strategic alliances and interfirm knowledge transfer. Strategic Management Journal 17, 77-91.

Nelson, R., 1988. Institutions supporting technical change in the United States. In: Dosi, G. (Ed)., Technical change and economic theory, Pinter Publishers, London, pp. 312-329. Nelson, R., 1993. National innovation systems: A comparative analysis. Oxford University Press, Oxford. 
Patel, P., Pavitt, K., 1995. Patterns of technological activity: their measurement and interpretation. In: Stoneman, P. (Ed)., Handbook of the economics of innovation and technological changes. Blackwell Publishers Ltd., Oxford, pp. 14-51.

Pavitt, K., 1985. Patent statistics as indicators of innovative activities: Possibilities and problems. Scientometrics 7 (1-2), 77-99.

Pritchard, D., MacPherson, A., 2004. Outsourcing US commercial aircraft technology and innovation: Implications for the industry’s long-term design and build capability. United States Trade Center, Department of Geography, Buffalo, NY.

Porter, M., 1990. The competitive advantage of nations. Free Press, New York.

Porter, M., 1998. Clusters and competition: New agendas for companies, governments, and institutions. In: Porter, M. (Ed)., On Competition, Havard Business School Press, Boston, MA, pp. 197-287.

Quelin, B., Duhamel, F., 2003. Bringing together strategic outsourcing and corporate strategy: outsourcing motives and risks. European Management Journal 21 (5), 647-661.

Quinn, J., 1999. Strategic outsourcing: Leveraging knowledge capabilities. Sloan Management Review 40 (4), 9-21.

Quinn, J., 2000. Outsourcing innovation: The new engine of growth. Sloan Management Review 41, 13-28.

Rare Earth Information Center, 2005. Institute for Physical Research and Technology. http://www.external.ameslab.gov/ric/Index.html.

Ricart, J., Enright, M., Ghemawat, P., Hart, S., Khanna, T., 2004. New frontiers in international strategy. Journal of International Business Studies 35, 175-200.

Romer, P., 1990. Endogenous technical change. Journal of Political Economy 98, 71-102. 
Slack, N., Lewis, M., 2002. Operations Strategy, FT Prentice Hall, London.

Stuart, T., Podolny, J., 1996. Local search and the evolution of technological capabilities. Strategic Management Journal 17, 21-38.

Tansey, B., 2004. Testing the offshore waters; Biotech firms experiment with moving work overseas. The San Francisco Chronicle.

Thibodeau, P., Lemon, S., 2004. R\&D starts to move offshore. Computerworld.

Trout, S., 2002. Rare earth magnet industry in the USA: Current status and future trends. XVII Rare Earth Magnet Workshop, Newark, DE.

USGS Minerals Information: Rare Earths, 2005. United States Geological Survey, http://minerals.usgs.gov/minerals/pubs/commodity/rare_earths/.

Venkatraman, N., 2004. Offshoring without guilt. MIT Sloan Management Review 45 (3), 1416.

Wybourne, B., 2004. The fascination of rare earths - then, now, and in the future. Journal of Alloys and Compounds 380, 96-100.

Zander, I., 2002. The formation of international innovation networks in the multinational corporation: An evolutionary perspective. Industrial and Corporate Change 11 (2), 327-353. 


\section{TABLES}

TABLE 1

Keywords employed for abstract-based keyword searches

\begin{tabular}{ll}
\hline Rare-earth Elements & Platinum Group Metals \\
\hline Rare Earth & Platinum, Pt \\
Lanthanide & Palladium, Pd \\
Lanthanum, La & Rhodium, Rh \\
Cerium, Ce & Osmium, Os \\
Praseodymium, Pr & Iridium, Ir \\
Neodymium, Nd & Ruthenium, Ru \\
Promethium, Pm & \\
Samarium, Sm & \\
Europium, Eu & \\
Gadolinium, Gd & \\
Terbium, Tb & \\
Dysprosium, Dy & \\
Holmium, Ho & \\
Erbium, Er & \\
Thulium, Tm & \\
Ytterbium, Yb & \\
Scandium, Sc & \\
Yttrium, Y & \\
Lutetium, Lu &
\end{tabular}


TABLE 2

Correlation and descriptive statistics for variables used in patent count analysis

\begin{tabular}{|c|c|c|c|c|c|c|c|}
\hline Model & Variable & Description & Mean & $S D$ & 1 & 2 & 3 \\
\hline \multirow{4}{*}{$\begin{array}{l}\text { 1. Active }{ }^{\mathrm{a}} \\
\text { (outliers removed) }\end{array}$} & 1. REPat & 0 - 1 dummy & 0.42 & 0.49 & & & \\
\hline & 2. $A P Y R$ & Application Year & 1989.82 & 7.55 & $0.10 * * *$ & & \\
\hline & 3. USsite & 0 - 1 dummy & 0.5 & 0.50 & $-0.05^{* * *}$ & $-0.18 * * *$ & \\
\hline & 4. $d_{1}$ & 0 - 1 dummy & 0.56 & 0.50 & $0.09 * * *$ & $0.86^{* * *}$ & $-0.16^{* * *}$ \\
\hline \multirow[t]{4}{*}{ 2. Top $100^{\mathrm{b}}$} & 1. REPat & 0 - 1 dummy & 0.41 & 0.49 & & & \\
\hline & 2. $A P Y R$ & Application Year & 1989.44 & 7.46 & $0.15^{* * *}$ & & \\
\hline & 3. USsite & 0 - 1 dummy & 0.52 & 0.50 & $-0.08^{* * *}$ & $-0.23 * * *$ & \\
\hline & 4. $d_{1}$ & 0 - 1 dummy & 0.49 & 0.50 & $0.11^{* * *}$ & $0.84^{* * *}$ & $-0.20 * * *$ \\
\hline \multirow[t]{4}{*}{ 3. Complete ${ }^{\mathrm{c}}$} & 1. REPat & 0 - 1 dummy & 0.43 & 0.49 & & & \\
\hline & 2. APYR & Application Year & 1990.22 & 7.59 & $0.08^{* * *}$ & & \\
\hline & 3. USsite & 0 - 1 dummy & 0.49 & 0.50 & $-0.05^{* * *}$ & $-0.15^{* * *}$ & \\
\hline & 4. $d_{1}$ & 0 - 1 dummy & 0.58 & 0.49 & $0.07 * * *$ & $0.86^{* * *}$ & $-0.13^{* * *}$ \\
\hline
\end{tabular}

a: $N=17067$

b: $N=11419$

c: $N=21378$

$* * * \mathrm{p}<0.001$

TABLE 3

Correlation and descriptive statistics for variables used in citation analysis

\begin{tabular}{|c|c|c|c|c|c|c|c|}
\hline Variable & Description & Mean & $S D$ & 1 & 2 & 3 & 4 \\
\hline 1. REPat & 0 - 1 dummy & 0.47 & 0.50 & & & & \\
\hline 2. CitingAPYR & Application Year & 1990.29 & 4.45 & $0.16^{* * *}$ & & & \\
\hline 3. CitingUSsite & 0 - 1 dummy & 0.510 & 0.50 & $-0.12 * * *$ & $-0.13^{* * *}$ & & \\
\hline 4. CitedUSsite & 0 - 1 dummy & 0.490 & 0.50 & $-0.05^{* * *}$ & $-0.09 * * *$ & $0.16^{* * *}$ & \\
\hline 5. $d_{1}$ & 0 - 1 dummy & 0.51 & 0.50 & $0.12^{* * *}$ & $0.85^{* * *}$ & $-0.10 * * *$ & $-0.06 * * *$ \\
\hline
\end{tabular}

$N=8289$

$* * * \mathrm{p}<0.001$ 


\section{TABLE 4}

\section{Regression results for patent count analysis}

Dependent Variable: USsite (patent) [0,1]

Propensity for innovation activity to be conducted within the US

\begin{tabular}{|c|c|c|c|c|c|c|}
\hline \multirow[b]{2}{*}{ Model Number } & \multicolumn{2}{|c|}{ 1. Active } & \multicolumn{2}{|c|}{ 2. Top 100} & \multicolumn{2}{|c|}{ 3. Complete } \\
\hline & (1a) & (1b) & (2a) & (2b) & (3a) & (3b) \\
\hline \multirow[t]{2}{*}{ Intercept } & $0.47 * * *$ & $0.57 * * *$ & $0.64 * * *$ & $0.79 * * *$ & $0.41 * * *$ & $0.51 * * *$ \\
\hline & $(0.03)$ & $(0.03)$ & $(0.03)$ & $(0.04)$ & $(0.02)$ & $(0.03)$ \\
\hline REPat & $-0.19 * * *$ & $-0.28 * * *$ & $-0.24 * * *$ & $-0.38 * * *$ & $-0.22 * * *$ & $-0.32 * * *$ \\
\hline Rare-earth patents & $(0.05)$ & $(0.06)$ & $(0.07)$ & $(0.07)$ & $(0.05)$ & $(0.05)$ \\
\hline$A P Y R$ & $-0.03 * * *$ & $-0.04 * * *$ & $-0.04 * * *$ & $-0.06 * * *$ & $-0.03 * * *$ & $-0.04 * * *$ \\
\hline Patent application year & $(0.002)$ & $(0.003)$ & $(0.002)$ & $(0.004)$ & $(0.001)$ & $(0.003)$ \\
\hline$d_{1} * A P Y R$ & & $0.03^{* * *}$ & & $0.05^{* * *}$ & & $0.03^{* * *}$ \\
\hline Patent trends after 1990 & & $(0.007)$ & & $(0.01)$ & & $(0.006)$ \\
\hline REPat*APYR & $-0.01 * *$ & $0.02 * * *$ & $0.02 * *$ & $0.04 * * *$ & $0.01 * *$ & $0.02 * * *$ \\
\hline Rare-earth patent trends & $(0.004)$ & $(0.005)$ & $(0.006)$ & $(0.007)$ & $(0.004)$ & $(0.005)$ \\
\hline$d_{1} * R E P a t * A P Y R$ & $-0.02 * *$ & $-0.05 * * *$ & $-0.045 * * *$ & $-0.09 * * *$ & -0.01 & $-0.04 * * *$ \\
\hline Rare-earth patent trends after 1990 & $(0.008)$ & $(0.01)$ & $(0.01)$ & $(0.01)$ & $(0.007)$ & $(0.01)$ \\
\hline Chi-square & $567.66^{* * *}$ & $586.29 * * *$ & $662.88 * * *$ & $688.84 * * *$ & $521.58 * * *$ & $544.09 * * *$ \\
\hline Observations & 17067 & 17067 & 11419 & 11419 & 21378 & 21378 \\
\hline \multicolumn{7}{|l|}{ Standard errors in parentheses } \\
\hline \multicolumn{7}{|l|}{$d_{1}=1$ if $A P Y R>1990$, else $=0$} \\
\hline \multicolumn{7}{|l|}{$\dagger \mathrm{p}<0.10$} \\
\hline \multicolumn{7}{|l|}{$* \mathrm{p}<0.05$} \\
\hline \multicolumn{7}{|l|}{$* * \mathrm{p}<0.01$} \\
\hline$* * * \mathrm{p}<0.001$ & & & & & & \\
\hline
\end{tabular}




\section{TABLE 5}

\section{Regression results for citation analysis}

Dependent Variable: CitedUSsite (patent) [0,1]

Propensity for patent to cite prior innovation developed in the US

\begin{tabular}{|c|c|c|c|c|c|}
\hline Int. No.I & Model Number & $(4 a)$ & (4b) & $(5 a)$ & (5b) \\
\hline & \multirow[t]{2}{*}{ Intercept } & -0.05 & -0.01 & -0.03 & -0.03 \\
\hline & & $(0.05)$ & $(0.06)$ & $(0.06)$ & $(0.05)$ \\
\hline & CitingUSsite & $0.38 * * *$ & $0.38 * * *$ & $0.38 * * *$ & $0.43^{* * *}$ \\
\hline & Citing patent assigned to US organization & $(0.03)$ & $(0.03)$ & $(0.07)$ & $(0.08)$ \\
\hline & CitingAPYR & $-0.02 * * *$ & $-0.03 * *$ & $-0.01 *$ & $-0.01 *$ \\
\hline & Citing patent application year & $(0.005)$ & $(0.01)$ & $(0.005)$ & $(0.005)$ \\
\hline \multirow[t]{4}{*}{1} & $d_{1} *$ Citing $A P Y R$ & & 0.02 & & \\
\hline & Patent trends after 1990 & & $(0.02)$ & & \\
\hline & REPat & -0.14 & $-0.18 \dagger$ & $-0.18 * * *$ & $-0.18 * * *$ \\
\hline & Rare-earth patents & $(0.09)$ & $(0.09)$ & $(0.04)$ & $(0.04)$ \\
\hline \multirow[t]{2}{*}{2} & CitingAPYR*REPat & 0.015 & $0.03 \dagger$ & & \\
\hline & Rare-earth patent trends & $(0.01)$ & $(0.016)$ & & \\
\hline \multirow[t]{2}{*}{3} & $d_{1} *$ CitingAPYR*REPat & -0.02 & $-0.05 \dagger$ & & \\
\hline & Rare-earth patent trends after 1990 & $(0.02)$ & $(0.03)$ & & \\
\hline \multirow[t]{2}{*}{4} & CitingAPYR*CitingUSsite & & & $-0.01 \dagger$ & $-0.03 *$ \\
\hline & US organization patent trends & & & $(0.01)$ & $(0.01)$ \\
\hline \multirow[t]{2}{*}{5} & $d_{1} *$ CitingAPYR*CitingUSsite & & & & 0.04 \\
\hline & US organization patent trends after 1990 & & & & $(0.03)$ \\
\hline \multirow[t]{2}{*}{6} & CitingAPYR*CitingUSsite*REPat & & & $0.04^{* * *}$ & $0.05^{* * *}$ \\
\hline & US organization rare-earth patent trends & & & $(0.01)$ & $(0.01)$ \\
\hline \multirow[t]{11}{*}{7} & $d_{1} *$ CitingAPYR $*$ CitingUSsite $*$ REPat & & & -0.04 & $-0.07 *$ \\
\hline & US organization rare-earth patent trends after 1990 & & & $(0.03)$ & $(0.03)$ \\
\hline & Log Likelihood & -5610.44 & -5609.25 & -5601.32 & -5598.53 \\
\hline & Chi-square & $8288.19 * * *$ & $8288.04 * * *$ & $8288.12^{* * *}$ & $8288.22 * * *$ \\
\hline & Observations & 8289 & 8289 & 8289 & 8289 \\
\hline & Robust standard errors in parentheses & & & & \\
\hline & $d_{1}=1$ if $A P Y R>1990$, else $=0$ & & & & \\
\hline & $\dagger \mathrm{p}<0.10$ & & & & \\
\hline & $* \mathrm{p}<0.05$ & & & & \\
\hline & $* * \mathrm{p}<0.01$ & & & & \\
\hline & $* * * \mathrm{p}<0.001$ & & & & \\
\hline
\end{tabular}




\section{FIGURES}

\section{FIGURE 1}

Global production of rare-earth oxides 1950 - 2003 (USGS)

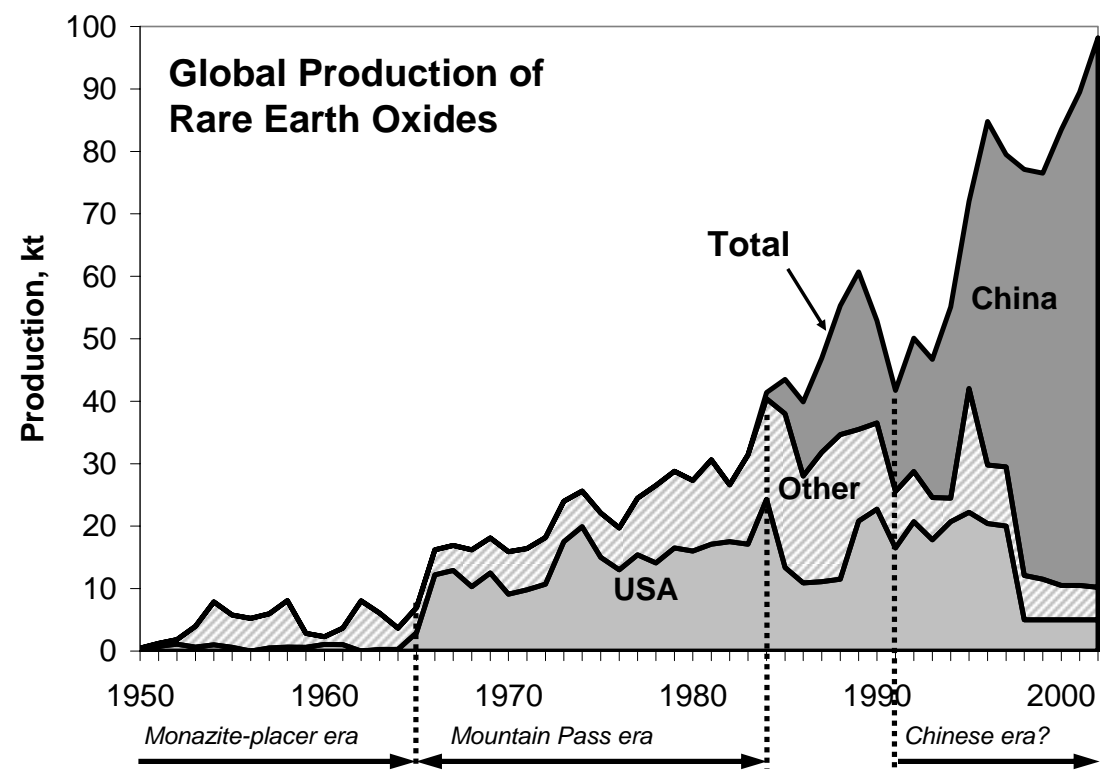

FIGURE 2

Global production of platinum group metals 1950 - 2003 (USGS)

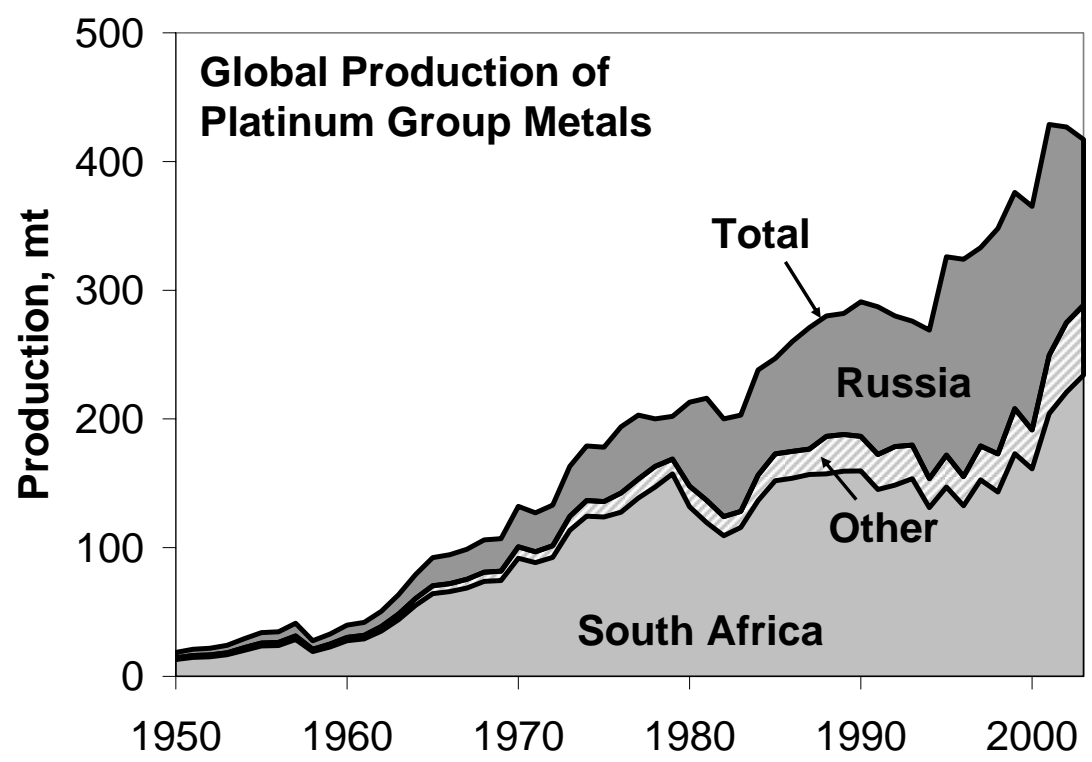




\section{FIGURE 3}

Plots of patent counts included in active data set by application year for rare-earth and platinum patents

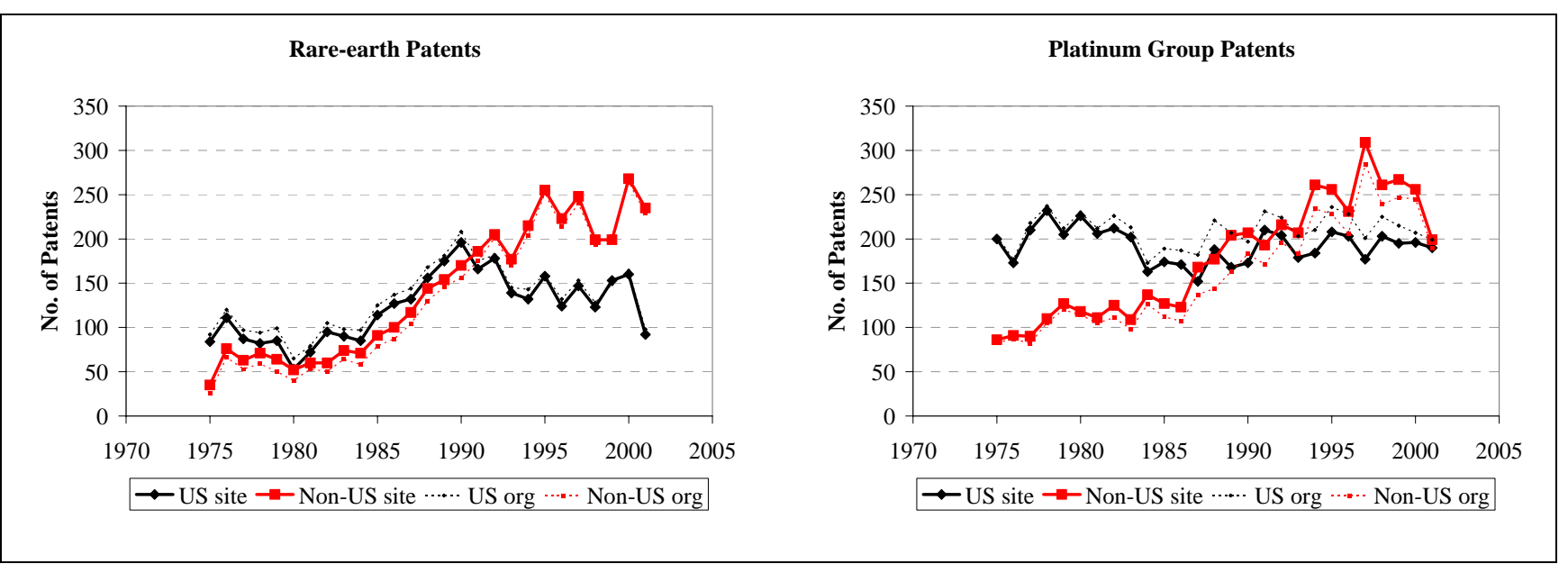

